\title{
DICIONÁRIO \\ ONLINE BILÍNGUE \\ LIBRAS/PORTUGUÊS: \\ REFLEXÕES SOBRE \\ A FORMAÇÃO DE \\ PROFESSORES DO \\ ENSINO \\ SUPERIOR
}

\section{DICCIONARIO BILINGÜE EN LÍNEA LENGUA BRASILEÑA DE SEÑAS/PORTUGUÉS: REFLEXIONES ACERCA DE LA FORMACIÓN DE PROFESORES EN LA EDUCACIÓN SUPERIOR}

ONLINE BILINGUAL LIBRAS/PORTUGUESE DICTIONARY: REFLEXIONS ABOUT TEACHER'S TRAINING OF HIGHER EDUCATION

Ana Luisa Borba Gediel* Bárbara Silveira Baptista de Oliveira** Lael Machado Rodrigues*** Universidade Federal de Viçosa

* Professora do Departamento de Letras, Universidade Federal de Viçosa, atuação na área de Libras e no Programa de Pós-Graduação em Letras, na linha de pesquisa em Linguística Aplicada: formação de professores e ensino e aprendizagem delínguas. E-mail: ana.gediel@ufv.br.

** Licencianda em Letras Português/ Inglês pela Universidade Federal de Viçosa. Atuação como bolsista de iniciação científica PIBIC/CNPq e atuação como professora-estagiária no Curso de Extensão em Libras - CELIB, Universidade FederaldeViçosa.E-mail: barbara.baptista@ufv.br. 
RESUMO: Este artigo apresenta uma análise do Dicionário Online Bilíngue Libras/Português, na perspectiva de professores do Ensino Superior, como uma ferramenta de apoio para a atividade inclusiva em uma Instituição de Ensino Superior da Zona da Mata Mineira. Esta pesquisa foi realizada por meio de uma metodologia qualitativa. A coleta de dados ocorreu a partir da realização de duas oficinas, de modo a atender às necessidades do grupo, visando às diferentes contribuições que os participantes poderiam prover. Os principais resultados demonstram o processo reflexivo dos professores em relação à necessidade de formação para a comunicação em sala de aula, assim como descrevem a socialização dos caminhos encontrados para a troca de conhecimentos e criação de sinais-termo para o acesso dos alunos Surdos aos conteúdos ministrados.

PALAVRAS-CHAVE: Libras. Dicionário. Professores.

RESUMEN: Este artículo presenta un análisis en relación al uso del Diccionario Bilingüe en Línea Lengua Brasileña de Señas/Portugués, desde la perspectiva de los maestros de la educación superior, como una herramienta de apoyo para la actividad inclusiva en una institución de educación superior en la Zona da Mata Mineira. Esta investigación se realizó a través de una metodología cualitativa. La recolección de datos se realizó a partir de la realización de dos talleres, con el fin de satisfacer las necesidades del grupo, centrándose en las diferentes contribuciones que los participantes podrían hacer. Los resultados principales demuestran el proceso reflexivo de los docentes en relación a la necesidad de capacitación para la comunicación en el aula, y describen la socialización de los caminos encontrados para el intercambio de conocimientos y la creación de señales-término para el acceso de los estudiantes sordos al contenido enseñado.

PALABRAS CLAVE: Libras. Diccionario. Maestros.

ABSTRACT: This article presents the potential of using Libras/Portuguese Online Bilingual Dictionary as a support tool for inclusive activity in the perspective of professors at Higher Education Institution in Zona da Mata, Minas Gerais State. For this, we used a qualitative methodology, in which the data collection occurred from the realization of two workshops, in order to meet the needs of the group, aiming at the different contributions that the participants could provide. As main results we can list the reflexions of the professors about the need of formation to achieve communication at the classroom, also they described the union of methodologies to teach Deaf students and the creation of specific signs to improve the information access to the Deaf students.

KEYWORDS: Libras. Dictionary. Professors.

\section{INTRODUÇÃO}

O presente trabalho visa apresentar reflexões geradas por professores que atuam no Ensino Superior (ES) sobre os processos de comunicação e de ensino-aprendizagem a partir da presença de alunos Surdos e da Língua Brasileira de Sinais - Libras. Este artigo é fruto de uma pesquisa interdisciplinar, realizada para a produção e desenvolvimento da plataforma denominada de Dicionário Online Bilíngue Libras/ Português ${ }^{1}$. O Dicionário foi criado para apoiar o processo de tradução da Libras para o Português e Português para Libras a partir de um software online com a inserção de sinais regionais básicos e um sinalário ${ }^{2}$ embasado no contexto acadêmico de alunos Surdos ${ }^{3}$ matriculados em uma Instituição de Ensino Superior (IES).

A pesquisa objetivou entender, a partir do olhar dos professores, como utilizar o Dicionário para mediar a comunicação nos processos de interação com os alunos Surdos em contexto de sala de aula a partir da realização de oficinas. Neste artigo, pontuamos a discussão gerada por meio da reflexão dos professores em relação à formação, às noções envolvendo a representação da Libras, além do acesso aos conteúdos, à necessidade de criação de estratégias para o entendimento de conceitos científicos e ao processo de

\footnotetext{
${ }^{1}$ O Dicionário Online Bilíngue Libras/ Português teve início com o apoio e financiamento do Edital CAPES Inovação 2015 e, posteriormente, teve seguimento com o Edital CAPES Inovação 2018. A partir desse trabalho inicial, vários outros projetos, inovações e parcerias foram concretizadas, também com o recebimento de financiamento institucional local, tendo em vista possibilitar a democratização à informação na educação aos alunos Surdos.

${ }^{2}$ De acordo com Malacarne e Oliveira (2018), “os sinalários são [...] resultado de criação e difusão de sinais, pois são determinados entre os constituintes da comunidade surda, surdos e ouvintes fluentes na Língua de Sinais”.

${ }^{3}$ Aderimos, neste artigo, à utilização da nomenclatura Surdo, com S maiúsculo, levando em consideração os aspectos políticos, culturais e linguísticos da comunidade Surda. Nesse sentido, o termo êmico Surdo demarca um posicionamento que é utilizado pelo grupo para designar os usuários da Libras como primeira língua (L1).
} 
interação com os alunos Surdos.

Este trabalho fez-se necessário pois, no que se refere ao ensino-aprendizagem dos Surdos, há obstáculos a serem trabalhados e superados. Entendemos que a viabilidade do processo de apreensão dos conhecimentos deve ocorrer por meio da primeira língua dos sujeitos, que para eles será a Língua Brasileira de Sinais (Libras). Essa afirmativa está de acordo com os pressupostos da educação bilíngue, que considera a Libras a primeira língua (L1) dos Surdos, a qual deve ser priorizada em relação ao Português (QUADROS, 2006). O estabelecimento do uso desta língua em sala de aula possibilita uma comunicação satisfatória e é entendido como uma das prerrogativas para chegarmos à uma educação de qualidade.

Apesar da ampliação de matrículas de Surdos nas IES brasileiras (DARQUE, 2011), com a Lei nº 13.409/2016 (BRASIL, 2016), a garantia de acesso não implica diretamente na permanência e na finalização dos cursos que esses alunos estão realizando. De acordo com Barbosa e Elias (2011), a educação dos Surdos ainda enfrenta desafios devido à barreira linguística presente entre o professor e o aluno. Para promover condições de permanência, é fundamental a adaptação no contexto do ES, gerando acessibilidade ao longo da formação. Tais adequações são demandadas a partir de mudanças metodológicas e de recursos nas aulas, por exemplo, a reorganização espacial das salas de aula, a elaboração de materiais acessíveis para auxiliar o aluno a estudar em casa e a presença do Tradutor e Intérprete de Língua de Sinais e Português (TILSP).

Nosso foco está naqueles professores ouvintes que atuam em diferentes cursos de Graduação e que não possuem conhecimento da Libras e, em grande maioria, da cultura Surda, dificultando o desenvolvimento de conhecimentos por meio da Libras aos alunos Surdos e o atendimento aos pressupostos da metodologia bilíngue ${ }^{4}$ (QUADROS, 2006). No universo do grupo pesquisado, nenhum dos professores teve uma formação voltada para a educação de Surdos, tendo em vista que essa formação é obrigatória apenas para estudantes de licenciatura, o que vêm ocorrendo desde o ano de 2010, e, além disso, muitos dos professores do ES são formados em cursos de bacharelado.

Para contextualizar o embasamento teórico do estudo, na segunda seção, apresentamos uma discussão usufruindo de alguns preceitos relativos à Linguística A plicada (LA). Pontuamos a formação de professores e a atuação em sala de aula com alunos Surdos, relacionando-a com algumas iniciativas que envolvem as Tecnologias de Informação e Comunicação (TICs) como possíveis ferramentas didáticas promotoras de inclusão e acessibilidade na sala de aula. Posteriormente, na seção três, descrevemos o método utilizado na pesquisa, apresentamos o Dicionário e os colaboradores. Em seguida, na quarta seção, delineamos as discussões levantadas por este trabalho, ou seja, as reflexões dos professores a partir do uso do Dicionário nas oficinas. Por fim, na seção cinco, ponderamos sobre a importância da formação docente no ES, no sentido de resposta e de estímulo ao desenvolvimento de políticas linguísticas.

\section{A AMPLIAÇÃO DOS ESTUDOS NA LINGUÍSTICA APLICADA E A INSERÇÃO DA LIBRAS}

Os estudos sobre a Linguística Aplicada (LA) iniciaram-se durante o período da Segunda Guerra Mundial, por volta dos anos 1940 , devido à demanda da época de aprimorar a docência das línguas estrangeiras, principalmente do Inglês (LOPES, 2011). Ao longo dos anos, o ensino de línguas estrangeiras foi sendo popularizado e considerado como um diferencial no mercado de trabalho, em uma dinâmica decorrente do processo de globalização e da demanda comunicacional entre países. Apesar de, atualmente, a Língua Inglesa ainda ser considerada a língua franca, Lopes (2011) salienta que o ensino de outras línguas foi democratizado, ganhando prestígio nos estudos da LA. Além disso, a LA passou a abarcar não somente a docência da segunda língua (L2), mas também os fatores que envolvem o processo de ensino e aprendizagem dos alunos.Nessa perspectiva, uma mudança significativa ocorre nos

\footnotetext{
${ }^{4}$ Definimos neste artigo bilinguismo a partir da definição de Skliar (1998), que argumenta que o conceito deve ser concebido de forma ampla, voltada para o direito de os surdos possuírem acesso à educação em sua língua minoritária. Desse modo, a primeira língua (L1) do Surdo é a Libras e esta seria a base de edificação escolar. Nesse sentido, o Surdo aprenderia a língua de sinais e teria a base curricular, metodológica e linguística alicerçada pelos pressupostos da cultura Surda durante a educação básica. Já no ensino superior, assim como amparado por lei (BRASIL, 2005), os alunos Surdos devem ser respeitados pelo uso da Libras como primeira língua e ter direito ao acesso de todos os conteúdos por meio dela. Desse modo, a presença de profissionais tradutores e intérpretes de Libras (TILSP) é imprescindível, além do conhecimento dos professores em relação às especificidades culturais e linguísticas de seus alunos para a adequação dos conteúdos, metodologias e avaliações.
} 
estudos em LA no Brasil nos anos 1980. Tal mudança diz respeito ao entendimento da interdisciplinaridade que passa a abranger discussões voltadas para questões de gênero, etnicidade, demandas de grupos sociais, assim como contribuições teóricometodológicas advindas da Sociologia, da Antropologia e da Psicologia (LOPES, 2011). Em adição, ampliam-se os conceitos que abrangem as práticas didáticas e pedagógicas, sendo concebidas a partir do contexto da "linguagem como prática social", em que os atores envolvidos são agentes desse processo, provenientes de culturas diversas, provocando mudanças no cotidiano (MENEZES et al., 2009).

Desde o ano de 2002, com a regulamentação da Libras como meio de comunicação legal da Comunidade Surda brasileira, a partir da Lei $n^{\circ}$ 10.436/2002 (BRASIL, 2002), um conjunto de reflexões passa a ser relevante para os estudos em LA. Souza e Barcelos (2016) catalogaram as principais temáticas derivadas dessas pesquisas a partir de uma investigação realizada em publicações de periódicos e em eixos temáticos do Congresso Brasileiro de Linguística Aplicada (CBLA). As autoras apontam que os temas envolvendo a Libras na LA aproximam-se das seguintes discussões: “[...] Análise do Discurso; Pragmática; Ensino e Aprendizagem de Língua Materna; Ensino e Aprendizagem de Línguas Adicionais; Formação de Professores; Letramentos; Linguagem e Tecnologia; Material Didático; Políticas Linguísticas; Sociolinguística; Tradução” (SOUZA; BARCELOS, 2016, p. 861).

Vários estudos vêm corroborando com os temas e discussões mapeados por Souza e Barcelos (2016). Gesser (2012) apresenta a discussão sobre o ensino e aprendizagem na educação de surdos por meio de práticas reflexivas; Silva et al. (2014) analisam o desenvolvimento de estratégias da comunicação escrita de surdos, relacionadas à Língua Portuguesa e à Língua Inglesa; Tavares e Oliveira (2014) discutem os desafios do ensino e aprendizagem no ensino do Inglês mediado pelas TICs em uma escola pública inclusiva; e Yatim e Pereira (2016) pautam a aprendizagem de Libras como L2 no Ensino Superior. Tais exemplos contribuem com temáticas vinculadas à Libras para o âmbito da $\mathrm{LA}^{5} \mathrm{e}$, dentre eles, descrevemos brevemente os estudos de Tavares e Oliveira (2016) e Yatim e Pereira (2016).

Tavares e Oliveira (2016) apresentam o olhar de professores, alunos e intérpretes, em relação ao ensino de inglês para surdos mediado por tecnologias e pela Libras. As autoras discutem a interação entre as três línguas em sala de aula onde os surdos aprendem o inglês e os ouvintes aprendem a Libras em um mesmo espaço. Tratam também da mediação feita pelo intérprete de Libras, cujo papel é traduzir o ambiente da sala de aula. Esse estudo aponta para a valorização do professor fluente na Libras em contraste com o que não possui conhecimentos nessa língua.

Yatim e Pereira (2016) investigam o aluno ouvinte do ES aprendendo a Libras a partir de um professor surdo. Tendo em vista a inserção da disciplina de Libras nos currículos dos estudantes de licenciatura e fonoaudiologia como obrigatória e, consequentemente, o maior contato das pessoas com a Libras. Apesar dos avanços da adição da disciplina na grade curricular dos cursos, os resultados apontam para a necessidade de melhorias como aumento da carga horária, criação de materiais didáticos e formação dos professores.

Com a ampliação dos estudos na LA, transcendeu-se a ideia de ensino e tradução de línguas estrangeiras, englobando as línguas consideradas maternas e adicionais, além das questões linguísticas como o letramento, as estratégias e metodologias de ensino, os processos interacionais, as relações culturais, abrangendo fatores sociais que circundam os usuários de determinada língua.

As contribuições das pesquisas no âmbito da LA apoiam minimizar problemáticas que emergem no século XXI, apresentando análises e discussões em que os grupos minoritários se tornam atores sociais, os processos interdisciplinares e a complexidade de diferentes elementos sociais, culturais, educacionais, que passam a estar vinculados à linguagem. É com esse olhar que nos identificamos no campo da LA e remetemos à questão da formação dos professores no ES.

${ }^{5}$ Nos estudos citados optamos por utilizar o termo surdo com "s" minúsculo, considerando as variáveis de sujeitos das pesquisas. 


\subsection{FORMAÇÃO DE PROFESSORES E LIBRAS: POSSIBILIDADES DE INCLUSÃO POR MEIO DAS TICS}

O professor tem papel central na busca por métodos e estratégias de ensino, pois é ele quem organiza a sala de aula e os recursos adequados para atender todos os alunos e suas demandas, para que possam, enfim, ter participação ativa em todo o contexto de sala de aula (DUBOC, 2005). Para isso, a formação de professores ${ }^{6}$ é uma prerrogativa a ser evidenciada em seus diferentes níveis, desde a formação inicial à formação continuada, inclusive envolvendo a formação continuada no ES.

A formação de professores, de acordo com David (2017), pressupõe um contexto acadêmico e didático, com trocas de conhecimentos a partir a elaboração de um plano de ação que gere qualidade no trabalho pedagógico. Especificamente sobre a formação continuada, o autor refere-se à construção de uma "competência didático-universitária", que envolve a formação didático-pedagógica e a apropriação dos diferentes espaços institucionais e afazeres universitários (DAVID, 2017). Esse processo considera a articulação entre as especificidades e demandas institucionais e as habilidades e área de formação do professor.

Levando em consideração o contexto diversificado da formação de professores universitários, nas diferentes áreas do saber, nota-se que a legislação traz algumas diretrizes, as quais se referem a formação continuada no ES na perspectiva da inclusão das pessoas Surdas ou com deficiência, tais como as Propostas de Diretrizes para a Formação Inicial de Professores da Educação Básica em cursos de nível superior, de abril de 2001 (BRASIL, 2001); e também apontam para o ES, como a resolução do Conselho Nacional de Educação/ Conselho Pleno (CNE/CP), de18 de fevereiro de 2002, que institui as Diretrizes Curriculares Nacionais para a Formação de Professores da Educação Básica em Nível Superior curso de licenciatura, de graduação plena. Há, ainda, o Decreto ${ }^{\circ}$ 5.626/2005 que, nos seus Artigos 23 e 24, no capítulo 4, regulamenta a garantia do direito à educação das pessoas surdas ou com deficiência auditiva no ES. Nesse sentido, é estabelecido na formação do professor a exigência de incorporação dos processos de integração dos diferentes grupos sociais, especialmente na educação inclusiva (DUBOC, 2005). A formação continuada é entendida como uma forma de refletir sobre os processos educacionais, a aprendizagem e a formação do próprio professor (GARRIDO, 1999).

Castanho e Freitas (2006, p.96) descrevem a importância da gestão universitária apontar caminhos e fornecer subsídios para o desenvolvimento da "prática pedagógica dos professores que atuam no Ensino Superior", levando em consideração as políticas inclusivas já existentes. As autoras ainda destacam que é premente que haja capacitação ao professor do contexto universitário, com o oferecimento propostas didáticas e pedagógicas para a criação de habilidades que possibilitem ações inclusivas.

Para promover condições de permanência, na formação continuada universitária é fundamental a adaptação no contexto educacional para gerar acessibilidade ao longo da formação (CASTANHO; FREITAS, 2006). Tais adequações são demandadas a partir de mudanças da metodologia das aulas, como, por exemplo, a necessidade de organização espacial das salas de aulas, de materiais acessíveis que possam auxiliar o aluno a estudar em casa, e, especialmente, a presença do TILSP para mediar o processo de ensino-aprendizagem no contexto de sala de aula.

Dentre esses elementos, observamos que as Tecnologias de Informação e Comunicação (TICs) ganham visibilidade como uma das ferramentas que apoiam a construção de espaço para debates acerca da Libras, da formação de professores e da educação de surdos na LA. Portanto, cabe à formação do professor dar a ele os meios necessários para fazer a mudança apropriada na sala de aula contribuindo para a melhoria da inclusão e da acessibilidade.

No caso dos Surdos, considerando sua cultura visual, essa adaptação pode ocorrer a partir de meios imagéticos para ilustrar o conteúdo, como fotos e vídeos e também pelo uso das TICs. Freire e Leffa (2013), apresentam a percepção de Paulo Freire frente às influências geradas pela tecnologia em âmbito educacional, visão esta que dá origem à denominação auto-heteroecoformação tecnológica, que consiste na "[...] ação do ambiente - presencial ou digital - sobre os indivíduos, mediada por ferramentas, práticas e linguagens singulares, aliada a uma ação crítico-reflexiva desses indivíduos sobre o meio [...]” (FREIRE; LEFFA, 2013, p. 75). Essa

\footnotetext{
${ }^{6}$ Entendemos o conceito de formação de professores a partir de uma perspectiva ampla, que envolve aspectos educacionais, sociais, econômicos e linguísticos. A partir disso, nos contempla o conceito descrito por Nóvoa (1997), de que a formação de professores pode ser compreendida através da abrangência de análise profissional, passando para uma análise do contexto pessoal do docente não limitada somente ao contexto educacional, mas estendida ao âmbito social como um todo.
} 
perspectiva enfatiza os movimentos de socialização entre aluno-professor-tecnologia, englobando, na formação dos envolvidos, uma melhor compreensão em práticas linguísticas.

No ambiente educacional, as TICs são uma importante ferramenta de acesso, transformação e produção de informações a partir da ajuda da internet e de bases de dados. No ambiente acadêmico, elas podem apoiar a aprendizagem e o desenvolvimento de capacidades através do uso de um software educacional ou do uso de atividades envolvendo a internet, computadores e outros fatores tecnológicos (PONTE, 2000). Em contexto pedagógico com a presença de alunos surdos, as TICs podem assumir um papel relevante devido à sua potencialidade de facilitar a interação entre professor e aluno surdo, além de trabalhar como recurso didático a ser explorado (MIRANDA et al, 2017).

As TICs se tornam aliadas no processo de formação educacional dos Surdos a partir do momento em que são utilizadas como ferramentas assistivas, promovendo a acessibilidade. Consideramos a afirmação de Silva e Campos (2010), que definem TICs como todas as tecnologias que interferem e mediam os processos comunicacionais em diversos contextos, sendo aplicado também ao ensino. Assim, a utilização das TICs no ensino pode auxiliar a comunicação em sala e otimizar o aprendizado dos alunos. A noção apresentada pelas autoras propicia o entendimento de que os instrumentos de informação - como dicionários, enciclopédias, artigos - juntamente às telas de computadores, celulares, televisores e outras tecnologias proporcionam modos diferenciados de interação com o mundo. Notamos, também, que o uso da tecnologia depende do entendimento de usabilidade, do letramento digital, da manutenção e do acesso às ferramentas tecnológicas.

As TICs podem ser utilizadas para apoiar os processos tradutórios de termos científicos, artigos e textos por meio da tradução automática de um avatar (GEDIEL et al, 2019). Citamos os aplicativos de tradução semiautomática da Língua Portuguesa para a Libras: o Hand Talk (iniciativa privada), o ProDeaf (iniciativa privada) e a ferramenta governamental VLibras, da Universidade Federal da Paraíba (UFPB) em parceria com outras instituições.

O HandTalk e o ProDeaf são plataformas de tradução simultânea do conteúdo em Português para Libras. O primeiro aplicativo possui o avatar denominado popularmente como Hugo, que é encarregado de realizar sinalizações através do comando escrito ou falado. Já o segundo foi englobado pelo HandTalk no ano de 2018 com o objetivo de unir esforços em busca de melhorias das plataformas. Ambos apresentam potenciais de inclusão e revolucionam a comunicação imediata via smartphone. No entanto, ainda há um caminho a ser investigado para suprir as necessidades comunicacionais, em que estudos remetem à limitações ligadas ao excessivo uso da datilologia no momento da tradução (CORRÊA et al., 2018).

O VLibras é uma ferramenta que resultou da parceria entre o Ministério do Planejamento, Desenvolvimento e Gestão (MP), através da Secretaria de Tecnologia da Informação (STI) e a Universidade Federal da Paraíba (UFPB). A estrutura do VLibras é formada por um conjunto de ferramentas computacionais de código aberto responsável por traduzir textos, áudios e vídeos para a Libras, tornando computadores, dispositivos móveis e plataformas web acessíveis para pessoas Surdas e favorecendo o aprendizado da língua por ouvintes.

Ademais, podemos descrever também os jogos inseridos nos Laboratórios Virtuais, desenvolvidos a partir da parceria do governo do estado de Minas Gerais, via Secretaria de Estado de Ciência, Tecnologia e Ensino, Universidade Aberta Integrada (UAITEC), com a Universidade Federal de Viçosa (UFV). Foram desenvolvidos jogos voltados para o ensino da Libras e para a formação continuada de professores (GEDIEL et al., 2019). Além dessa iniciativa, outros trabalhos foram desenvolvidos na mesma IES de forma interdisciplinar, para a produção de aulas sinalizadas, as quais foram criadas em substituição às aulas narradas para o acesso dos alunos Surdos à IES (SOUZA; JÚNIOR, 2016).

A produção de recursos e materiais didáticos adequados às especificidades dos Surdos torna-se condutora do processo de ensinoaprendizagem. Tal elaboração deve evidenciar a valorização da modalidade visual-espacial, modalidade linguística da Libras. Em contexto pedagógico com a presença de alunos Surdos, as TICs podem assumir um papel relevante devido à sua potencialidade de facilitar a interação entre professor e aluno Surdo, além de trabalhar como recurso didático a ser explorado (MIRANDA et al., 2017). 
A inclusão de tecnologias educacionais deve ser realizada de forma planejada, coesa e contextualizada, sendo ideal que o educador passe por uma capacitação a respeito de como aplicar essas tecnologias através de práticas pedagógicas. É importante atentar para os fatores técnicos da implementação e para as condições de espaço ideal para a realização dessa troca. Morán (2013) argumenta que as tecnologias permitem a integração de tempo/espaço por meio do mundo digital, entretanto, é necessário que haja uma conexão de saberes em relação ao ambiente virtual para que este seja considerado um agente mediador efetivo.

\section{METODOLOGIA}

A escolha pela metodologia qualitativa ocorreu a partir da preocupação em entender como o Dicionário Online Bilíngue Libras/Português pode ser utilizado no contexto de sala de aula a partir da perspectiva dos participantes, visto que a ferramenta se encontra disponível ao público em geral para acesso, além de contar com o desenvolvimento contínuo a partir de pesquisas aplicadas no ensino superior. A partir dela, observamos os desafios, as complexidades, as vantagens e as desvantagens da implementação da ferramenta por meio de um contato estabelecido com os participantes (MINAYO, 1993).

A coleta de dados foi organizada através de uma oficina que foi realizada duas vezes, de acordo com a disponibilidade dos colaboradores. Para a seleção dos participantes, realizou-se o levantamento dos professores que estavam ministrando aulas para alunos Surdos durante o primeiro período letivo de 2019, conforme o calendário da IES. A instituição contava com três alunos Surdos no campi investigado. Após a realização do mapeamento com dados fornecidos pela secretaria responsável pela relação de professores, foram identificados dez docentes.

Posteriormente, foram enviados e-mails com o convite para participação na oficina intitulada "O Dicionário de Libras como ferramenta pedagógica inclusiva”. Dentre os convidados, quatro se disponibilizaram a contribuir com a pesquisa. Os nomes dos participantes e das disciplinas que ministram, apresentados no quadro abaixo, são fictícios para resguardar suas identidades, conforme descrição no Termo de Consentimento Livre e Esclarecido (TCLE) e aprovação pelo Comitê de Ética e Pesquisa (CEP) da IES 7 . Como não foi possível a concentração dos horários, foram realizadas duas oficinas, tendo os seguintes participantes:

\begin{tabular}{c|c|c} 
Nome do professor & Disciplina & Oficina \\
\hline Quiron & Resistência de Estruturas & Oficina 1 \\
\hline Perseu & Resistência de Estruturas & Oficina 1 \\
\hline Arthur & Transporte de Fluidos & Oficina 2 \\
\hline Otelo & Transporte de Fluidos & Oficina 2
\end{tabular}

Quadro 1: Nome dos professores participantes e suas respectivas disciplinas

Fonte: elaborado pelos autores (2019)

As oficinas ocorreram no período de 2019/1 em um laboratório de informática, para que todos os participantes tivessem acesso a computadores com internet. Os autores deste trabalho coordenaram a oficina, sendo cada um responsável por uma das seguintes

${ }^{7}$ A pesquisa passou pelo processo do CEP, via Plataforma Brasil, e foi registrada com o seguinte CAAE 81077317.6.0000.5153. 
funções: (i) ministrar as oficinas, apresentar a proposta e explicar a teoria base, tirando as dúvidas dos participantes e especificando as atividades; e (ii) observar, filmar e fazer notas sobre a interação dos participantes com a ferramenta e o ambiente da oficina. A escolha por filmar as oficinas se justifica pela necessidade de interpretar e observar o comportamento, as expressões faciais e corporais, as facilidades e as dificuldades dos participantes ao realizarem um sinal e demais interações visuais. Portanto, os dados foram catalogados e organizados a partir da transcrição dos vídeos, juntamente às anotações feitas durante e após as oficinas sobre a interação dos participantes (SÁ-SILVA et al., 2009).

A oficina foi estruturada em quatro momentos: (i) apresentação da pesquisa e dos integrantes e participantes da oficina; (ii) explicação teórica sobre a gramática da Libras, incluindo os cinco parâmetros fonológicos; (iii) realização de atividades baseadas na busca de sinais no Dicionário e organização de frases a partir de dinâmica para interligar um sinal à imagem de sua realização; e (iv) discussões a respeito do uso do Dicionário (pontos negativos, positivos e características a serem aprimoradas) e de metodologias que auxiliem na troca de experiência em sala de aula.

\subsection{O DICIONÁRIO ONLINE BILÍNGUE LIBRAS/PORTUGUÊS}

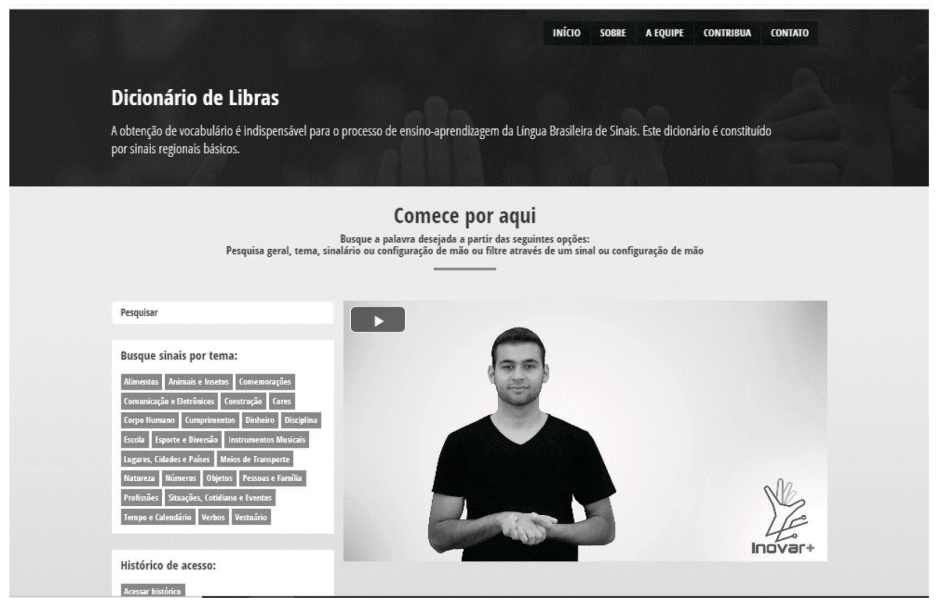

Figura 1: Apresentação do Dicionário

Fonte: CEAD UFV (2021)

O Dicionário Online Bilíngue Libras/Português ${ }^{8}$ é um software criado com o propósito de utilização enquanto ferramenta comunicacional, no sentido de auxiliar no processo de ensino e aprendizagem da Libras em diferentes instâncias do Ensino Superior, visando oferecer suporte aos desafios de permanência dos estudantes Surdos via computadores ou smartphones. Ele está disponível para livre acesso desde o dia 26 de setembro de 2019 e ainda está em processo de aprimoramento, como a inserção de sinais, possuindo ainda um acervo restrito. A partir de seu layout é possível realizar a busca por temas, observar a aplicabilidade dos sinais a partir de frases em Libras e consultar um sinalário com termos específicos de diferentes áreas do conhecimento.

O Dicionário possui uma barra de pesquisa onde são inseridas as palavras em português para a busca do sinal. Abaixo da barra de pesquisa estão os temas dos verbetes disponíveis no dicionário e, sendo assim, não é necessária a busca apenas pela palavra em português, pois pode-se encontrar a palavra desejada a partir do tema onde ela se encontra. A busca por configuração de mão contribui para a característica bilíngue do Dicionário, pois, dessa maneira, surdos que não sabem português podem utilizá-lo para pesquisar a tradução de palavras em sua L1. A busca a partir da configuração de mão se justifica por ser um dos cinco fatores fonológicos da Libras e o único que coube no formato do Dicionário.

\footnotetext{
${ }^{8}$ O Dicionário é fruto do trabalho de uma equipe multidisciplinar, envolvendo estudantes, professores e técnicos da Universidade Federal de Viçosa, por meio dos Departamentos de Letras, Ciências Sociais, Departamento de Biologia Geral, Informática e a Coordenadoria de Educação a Distância, além do apoio dos TILSP/UFV. O trabalho é reconhecido por sua aplicabilidade na instituição educacional, apoiando a acessibilidade dos alunos surdos aos conteúdos.
} 

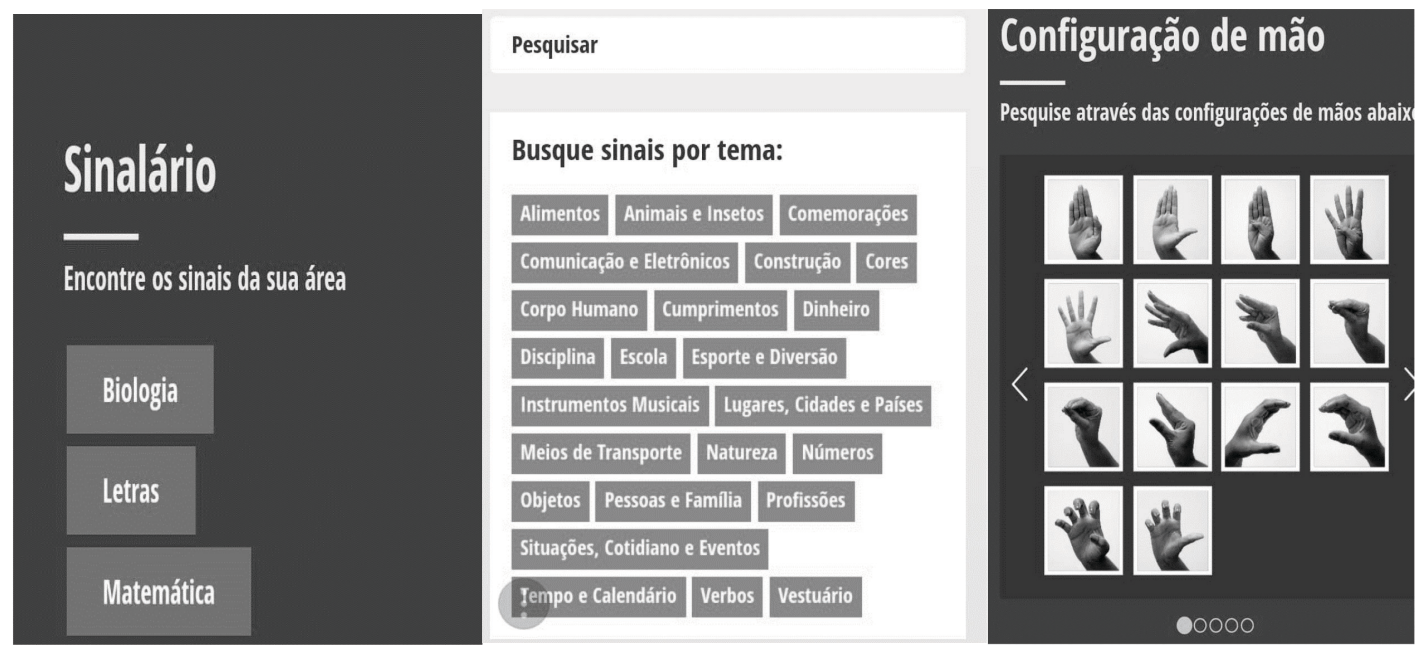

Figura 2: Layout de opções de busca do Dicionário

Fonte: CEAD UFV (2021)

Por ser um dicionário voltado para fins pedagógicos, também há uma busca a partir dos sinalários, ou seja, um conjunto de sinais correspondentes a uma área do conhecimento. Até o momento, o dicionário conta apenas com três áreas nos sinalários: Biologia, Letras e Matemática, porém, a partir das pesquisas do Projeto Inovar +, será possível adicionar outros temas de áreas do conhecimento.

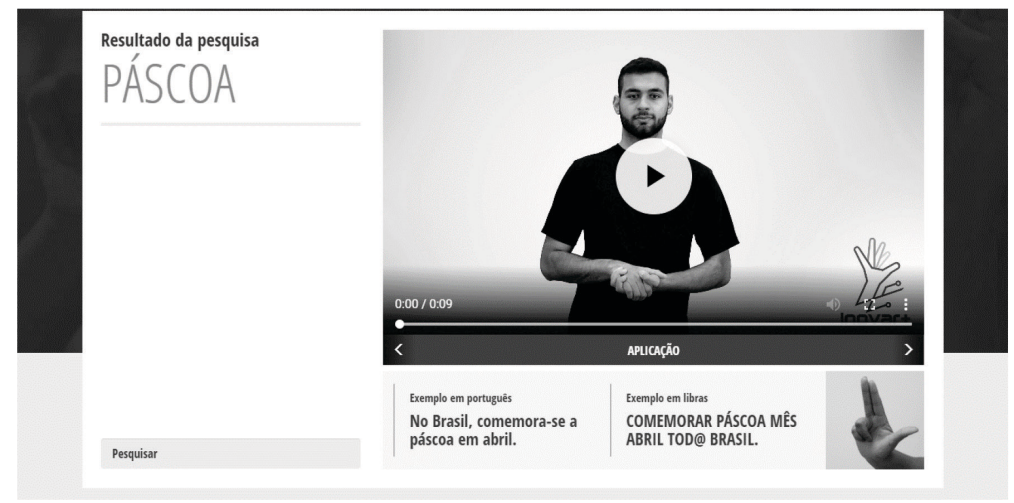

Figura 3: Exemplo de frase em Libras

Fonte: CEAD UFV (2021)

Nas páginas dos verbetes, além de vídeos do sinal e de suas variações, há a aplicação da palavra em uma frase em português e, ao seu lado, a mesma frase em glosa. Próximo às frases, há a configuração de mão correspondente ao sinal. Por fim, ao clicarmos na seta abaixo do vídeo, encontraremos uma sinalização da frase que contém o verbete.

\section{DISCUSSÃO E ANÁLISE DOS DADOS}

A partir dos momentos propostos para desenvolver a oficina surgiram diversas reflexões que incitaram debates para entender o contexto de sala de aula com a presença do aluno Surdo e versaram sobre o que é a Libras, sobre o processo de criação de sinaistermo, sobre a importância da formação docente e sobre a inserção dos Surdos no ES. Sendo assim, os resultados da pesquisa evidenciam a socialização dos caminhos encontrados pelos professores para a atuação em sala de aula. 


\subsection{O OLHAR DOS PROFESSORES EM RELAÇÃO À LIBRAS E AOS ALUNOS SURDOS: A OFICINA COMO LUGAR DE FORMAÇÃO}

Ao apresentar o segundo momento da oficina, ocorreu a explanação acerca dos cinco parâmetros fonológicos da Libras baseados nos estudos de Quadros e Karnopp (2004) e Brito (1995), apresentando mitos e crenças que envolvem o processo de ensino e aprendizagem das pessoas surdas e o reconhecimento da Libras como língua (GESSER, 2009). O objetivo da explicação foi evidenciar a utilização da configuração de mão ${ }^{9}$ como meio de busca de sinais no Dicionário. Nesse momento, surgiram questões voltadas para os conhecimentos que envolvem o ensino e aprendizagem da Libras e suas especificidades gramaticais.

Durante a explicação gramatical da Libras os professores manifestaram grande interesse em usufruir da oficina como uma formação em relação à língua. Houve interação dos participantes com apontamentos e perguntas referentes aos mitos e crenças, como pontua Perseu:

É bem diferente, essa gramática. Pelo que eu tô vendo aí tem alguma diferença, por exemplo, se é Língua Brasileira de Sinais, brasileira né? Mas o que eu vejo por essa questão de configuração de mão se torna uma língua independente da língua oral, não é só soletração. O sinal é um conceito. Isso pode ajudar muito em sala. (Perseu, oficina 1)

Ao iniciar sua constatação, o professor remete a um dos mitos mais usuais para iniciantes no contato com a língua e seu processo de ensino e aprendizagem. O questionamento do professor sobre a Libras ser brasileira remete ao mito da universalidade das línguas de sinais. Ou seja, a existência de uma única língua, que poderia ser usada em todo o mundo, sem variações linguísticas ou culturais. Entretanto, sabemos da existência de inúmeras línguas de sinais ao redor do mundo e das variações linguísticas, sejam elas regionais, sociais ou históricas (GESSER, 2009).

Além da questão da universalidade da língua, o entendimento de que não há uma gramática ou que todos os sinais são criados de forma icônica também constituem os mitos. Perseu descreve a diferença entre a sinalização e a datilologia, distanciando-se da crença de que a comunicação pode ser estabelecida a partir da soletração do alfabeto manual ${ }^{10}$. De acordo com Xavier e Barbosa (2014), baseando-se em estudos gramaticais da Língua de Sinais Americana (American Sign Language - ASL), a sinalização ocorre por meio dos parâmetros articulatórios ${ }^{11}$, como a configuração de mão, movimento, localização, marcação não manual e arranjo das mãos. Segundo os autores, o léxico dos sinais é composto a partir da combinação desses diferentes parâmetros.

Após a explicação, os professores entenderam como é constituída a gramática da Libras, gerando apontamentos como o de Arthur: "a forma como todas as informações estão dispostas [no Dicionário] ajuda bastante. Como vocês disseram, o Surdo é muito visual, e isso é importante. E também por se tratar de um Dicionário Bilíngue, essas mãos [configuração de mãos] aqui apoiam na pesquisa deles com a Libras" (Arthur, oficina 2). Em sua fala, o professor identifica a diferença da modalidade linguística da Libras como visuo-espacial, demonstrando que a visão é relevante para a apreensão dos conhecimentos, assim como conclui sobre o uso das configurações de mão como um dos parâmetros que potencializa o acesso da pessoa surda ao Dicionário, visto que elas são comuns à sua forma de comunicação no cotidiano.

No decorrer de toda a oficina, os professores refletiram sobre o aprendizado e tiraram dúvidas a respeito do tema, também fizeram comentários e deram depoimentos sobre as suas experiências em sala de aula. Arthur direciona a pergunta para entender sobre a criação de sinais. No entanto, demonstra sua pouca familiaridade em relação à Libras ao utilizar o termo "código" para se referir ao sinal. Por um lado, é possível perceber o distanciamento em relação ao status linguístico da Libras ao substituir "sinal" por "código", que pode ser assimilado também como "gesto", distanciando-se da ideia de "significado" e de "conceito", por exemplo. Como aponta Stelle e Strieichen (2013), grande parte do público ouvinte inserido no contexto inicial da Libras comete equívocos em

\footnotetext{
${ }^{9}$ Citando Brito (1995), as CM são as diversas formas que as mãos podem tomar na sinalização.

${ }^{10} \mathrm{O}$ alfabeto manual ou datilológico consiste no uso da soletração de sinais, nomes próprios ou termos que não possuam sinal com o uso de letras na Libras.

${ }^{11}$ Quadros e Karnopp (2004, p. 51) definem os parâmetros fonológicos da Libras como "articuladores primários para a composição da sinalização".
} 
nomenclaturas, como a utilização do termo "linguagem de sinais" ao invés de "língua de sinais".

Em contrapartida, chamamos atenção para as reflexões que os professores passaram a ter durante a oficina, eles possuíam questionamentos que contribuíram para repensar as práticas de ensino e aprendizagem de conteúdos acadêmicos, tendo em vista o acesso a esses conhecimentos pelo aluno Surdo. Arthur busca o entendimento sobre a forma de criação e de padronização de sinaistermo ${ }^{12}$ no contexto do sinalário, refletindo sobre a diferenciação das noções de significado e conceito. Em adição, o questionamento acerca da criação de sinais, apresenta o interesse dos professores em auxiliar os alunos na criação dos sinais combinados e como ocorre este processo.

Na IES estudada, os professores, ou monitores das disciplinas, se reúnem com os intérpretes e com o aluno Surdo e, em conjunto, os profissionais explicam e esclarecem os conceitos para o aluno a fim de que ele crie sinais adequados para termos que não possuem um sinal oficial. A importância desse processo é descrita por Pimenta et al., (2018), apontando para a criação de laços de confiabilidade entre os agentes envolvidos e os sinais-termo que estão sendo elaborados. Apesar dos entraves iniciais e do distanciamento dos professores dos conhecimentos relativos à Libras, os participantes tentaram auxiliar os alunos a partir da mediação com os intérpretes. Para isso, apresentaram termos que seriam utilizados em sala de aula e explicaram o seu significado, para que fosse possível apresentar o conteúdo previamente para o aluno Surdo e este criar um sinal combinado para o termo científico em questão.

No momento em que os participantes estavam procurando por sinais no Dicionário, eles debateram sobre a eficiência desse "combinado" entre o aluno e o intérprete. Foi observado que os professores acreditam que essa não é a melhor alternativa para o aprendizado do aluno: "Talvez sair criando gestos não seja a melhor forma né?! Em outros lugares devem ter isso feito e aceito de forma oficial já, o que precisa ser feito é estabelecer contato". (Arthur, oficina 2). Uma vez que a entrada de alunos Surdos nos cursos de graduação é recente, o processo de criação de sinais-termo ocorre de forma combinada, a partir da vivência do Surdo em sala de aula e o entendimento do significado dos conceitos que estão sendo trabalhados. Assim, há o estabelecimento de um elo entre o conceito científico do termo estudado e a sinalização.

Durante a descrição das características, especificidades e limitações do Dicionário, foi retomada a discussão sobre o desenvolvimento do sinalário, que avança de acordo com as demandas da instituição. A partir disso, os professores apontaram para a capacidade de abrangência da criação de sinais de termos específicos e descreveram a complexidade para explicar os conteúdos para o aluno Surdo, conforme Arthur, participante da oficina 2, aponta: "Mas tem uma palavra que é específica e aí não tem um código para ela, a criação desse sinal tem um padrão?”. Sobre isso, Faulstich (1995) descreve que, nas etapas de elaboração de um sinal-termo, devemos atentar para pontos importantes, que são: a) o público a qual o estudo se dirige; b) a área específica do conhecimento a qual o sinal se insere; e c) sistematização dos dados obtidos em forma de glossário. Assim, os sinais-termo terão sua formação a partir do conceito expresso para o termo referente.

Outro professor cita suas experiências vividas com o aluno Surdo, evidenciando que a necessidade de criação de sinais ocorre de forma constante em todas as aulas, uma vez que ele e o intérprete não conseguem se apoiar apenas nos sinais abarcados na Libras, $o$ que faz com que passem a combinar sinais, conforme a fala do professor: "Entendi. Mas não é bom este combinado né? Quer dizer, facilita naquele momento, mas dificulta o entendimento com o uso dos oficiais." (Otelo, oficina 2). Nesse aspecto, os professores demonstraram o entendimento dos limites de atuação dos atores envolvidos no processo comunicacional em sala (professorintérprete-aluno Surdo). Assim, os participantes observaram no Dicionário a capacidade de catalogação de sinais oficiais e a inserção de variantes para que o processo de criação ocorra de forma acelerada, de acordo com a necessidade de ingresso dos Surdos nas IES (PIMENTA et al., 2018).

Durante o último momento da oficina, os participantes responderam perguntas sobre o cotidiano na sala de aula, e foi possível identificar nas falas o desconforto pela barreira linguística existente entre professor e aluno. Os professores apontaram diversas vezes

${ }^{12}$ De acordo com Faulstich (2014), os sinais-termo “[...] representam conceitos com características de linguagem especializada, próprias de classe de objetos, de relações ou de entidades". 
a vontade que possuem de se comunicar com seu aluno sem a necessidade de mediação de um intérprete, como podemos observar na fala de Arthur:

[...] o ideal é que nós conseguíssemos nos comunicar independente do intérprete. Porque o intérprete acaba sendo algo no processo na medida que o normal seria que ambos entendêssemos a linguagem. Então eu acredito que isso facilita muito no diálogo entre nós docentes e o aluno sem a obrigatoriedade de um intérprete. Um diálogo em uma sala, esclarecer uma dúvida, eu acho que fica muito mais fácil, para que a gente possa, efetivamente, se comunicar. (Arthur, oficina 2)

Segundo Silva et al. (2009), apesar da presença do intérprete, o cenário ideal para o aprendizado do aluno Surdo é um professor com conhecimento na Libras. Arthur identificou essa problemática a partir de sua vivência em sala de aula, chegando a mesma conclusão das autoras. Nesse sentido, o professor Arthur, enxerga no Dicionário a possibilidade de se comunicar com o seu aluno Surdo. Assim, a TIC funcionaria como uma ponte, um apoio comunicacional entre professor e aluno, mediando a comunicação ao mesmo tempo em que auxiliaria a formação do professor aproximando-o de seu aluno (ABREU, 2010).

Ainda, esse momento da oficina levou a discussões sobre o impacto das práticas formativas e os professores apontaram a necessidade de haver um curso para sua formação. Em resposta a essa demanda, durante a realização da pesquisa, procuramos a existência de cursos para formação dos professores no IES.

Foi-nos informado, pelo setor responsável por esse serviço na instituição, sobre a realização de capacitação para os técnicos administrativos da IES, para o atendimento ao público em Libras. O setor e a própria gestão administrativa apontaram a importância da organização de futuros cursos destinados aos professores e buscaram o desenvolvimento de ações conjuntas ao setor de Libras. Esse retorno demonstra um dos resultados da realização de pesquisa e sua aplicação nas práticas.

Lopes (2011) propõe um olhar para a Linguística Aplicada de forma transdisciplinar e complexa, em que sugerimos aqui a pesquisa como um dos caminhos de reflexão acerca da formação. Esse processo requer um esforço colaborativo, assim como indicado pelo autor, para que a compreensão das práticas aconteçam e gerem implicações nas pesquisas e nas comunidades envolvidas.

É importante ressaltar que o Decreto $n^{\circ}$ 5.626/2005 enfatiza a formação continuada dos professores que atuam nas Instituições Federais de Ensino (IFES) de nível básico e superior, visto que trata da necessidade de que os professores tenham acesso à literatura e outras informações sobre a especificidade linguística do aluno Surdo, conforme disposto:

Art. 23. As instituições federais de ensino, de educação básica e superior, devem proporcionar aos alunos surdos os serviços de tradutor e intérprete de Libras - Língua Portuguesa em sala de aula e em outros espaços educacionais, bem como equipamentos e tecnologias que viabilizem o acesso à comunicação, à informação e à educação.

$\$ 1^{\circ}$ Deve ser proporcionado aos professores acesso à literatura e informações sobre a especificidade lingüística do aluno surdo

$\S 2^{\circ}$ As instituições privadas e as públicas dos sistemas de ensino federal, estadual, municipal e do Distrito Federal buscarão implementar as medidas referidas neste artigo como meio de assegurar aos alunos surdos ou com deficiência auditiva o acesso à comunicação, à informação e à educação.

Art. 24. A programação visual dos cursos de nível médio e superior, preferencialmente os de formação de professores, na modalidade de educação a distância, deve dispor de sistemas de acesso à informação como janela com tradutor e intérprete de Libras - Língua Portuguesa e subtitulação por meio do sistema de legenda oculta, de modo a reproduzir as mensagens veiculadas às pessoas surdas, conforme prevê o Decreto no 5.296, de 2 de dezembro de 2004. 
Nesse sentido, percebemos a importância dessa formação, visto que, um dos fatores para a exclusão social das pessoas surdas é a falta de conhecimento dos demais indivíduos da população a respeito da Libras e da surdez (QUADROS, 2003). Ainda, o Decreto no 7.611, de novembro 2011, específico sobre a Educação Superior, pontua a respeito da obrigatoriedade da estruturação de núcleos de acessibilidade nos IFES de ES visando eliminar barreiras físicas, de comunicação e de informação que restringem a participação e o desenvolvimento acadêmico e social de estudantes com deficiência.

As iniciativas governamentais apoiam diretrizes para a formação de professores, direcionando melhorias de acesso à educação. Embora os professores participantes desta pesquisa não tivessem participado de nenhum tipo de formação para serem professores de alunos Surdos, estavam interessados no processo de inclusão. Assim, levando em consideração o disposto na legislação, algumas implementações já vêm sendo realizadas - a exemplo disso, mencionamos o acesso à comunicação por meio dos profissionais tradutores intérpretes -, enquanto outras necessitam ser desenvolvidas, como a utilização de estratégias de ensino que usufruam de recursos visuais, os quais podem ser atrelados ao uso das TICs.

Compreendemos, a partir das reflexões dos professores, a sensibilização para a implementação de metodologias que tornem os conteúdos e conhecimentos da disciplina mais acessíveis. No entanto, os resultados da pesquisa demonstram como ainda é lenta a efetivação da equidade educacional para Surdos na ES. Ainda temos um caminho de pesquisas e iniciativas a serem seguidas para a efetivação da Lei 13.409/2016 (BRASIL, 2016). Embora seja possível constatar empiricamente o aumento do número de matrículas de alunos Surdos, a inserção desse público na graduação não é diretamente compatível com as oportunidades oferecidas para permanência e finalização dos cursos.

A falta de formação dos docentes que atuam no ES prejudica a formação dos alunos Surdos, uma vez que os professores, além de não possuírem uma formação linguística, também não conhecem metodologias que possam auxiliar no acesso aos conhecimentos desses alunos. Acreditamos, assim, que uma formação continuada para que os professores tenham ciência das especificidades culturais, históricas e linguísticas dos alunos Surdos seria uma alternativa para apoiar a inclusão desse grupo. O participante Otelo remete à falta de iniciativas da Universidade para auxiliar os professores com metodologias que ajudem o aluno Surdo com o conteúdo:

Uma coisa eu conversei até com o rapaz que é o chefe do setor de Libras, seria fazer uma reunião no início do semestre, sabe. Uma reunião fisicamente mesmo, porque via e-mail, a gente lê o e-mail às vezes, mas você recebe tantos e-mails, e aí demonstrar, passar o sentimento, dessa questão da Libras. Eu parei aqui pra me atentar que portuguêsé a segunda língua dele depois que eu comecei a dar aula, nem tinha me atentado sabe, pra essas coisas. (Otelo, oficina 2)

Percebemos por meio de sua fala sentimentos de insegurança e a demanda pela aprendizagem da Libras, levando-o a sugerir uma reunião na qual pudesse ocorrer novas trocas de conhecimentos. Otelo recorre a uma iniciativa a partir do incômodo gerado de ter a inviabilidade linguística de comunicação com um aluno em sala de aula. Desse modo, recorre a diferentes instâncias e setores institucionais, assim mencionado por David (2017), a partir de um desafio que foi gerado com a presença de um aluno surdo, busca alternativas para alcançar o aprendizado a todos os alunos.

A partir da dificuldade enfrentada, Otelo passou a entender melhor a realidade de seu aluno, uma evidência disso é o fato de ele perceber que a Libras é a L1 do Surdo, e não o Português. O colaborador da pesquisa remete a uma questão que é amparada por Quadros e Schmiedt (2006), em que a Libras deve ser priorizada em consonância ao Português como recurso linguístico. O estabelecimento de uma comunicação satisfatória depende do uso da Libras como principal meio linguístico nesse processo.

O professor mostra estar ciente da falta de sinais de áreas específicas do conhecimento, principalmente, na sua área de atuação: "A gente está fazendo reuniões semanais com as intérpretes para adiantar os termos que serão dados em aula. Para tentar criar um conceito, então ela já vai sabendo o conteúdo mesmo porque é nova né, é difícil." (Arthur, oficina 2). Percebemos que ocorre a interação professor-intérprete em sala de aula, em momentos anteriores às aulas, como meio de preparação do material a ser utilizado e elaboração de estratégias de ensino que possam dar acesso aos conteúdos para os alunos Surdos. 
Na maioria das vezes, a interação entre professor e o aluno Surdo se torna dependente da mediação do TILSP, que irá comunicar os conteúdos que estão sendo desenvolvidos - pelo professor - em Língua Portuguesa para a Libras durante as aulas. Durante o processo de tradução e interpretação, várias lacunas podem surgir quando são tratados conceitos e termos abstratos. Essa é uma grande preocupação para as instituições que recebem esse público, uma vez que a carência de sinais em Libras referentes às áreas científicas é elevada (VARGAS; GOBARA, 2013).

Para o fechamento da oficina, foram distribuídas perguntas que visavam gerar discussões em relação às possibilidades de uso do Dicionário como ferramenta didática. Os professores apontaram a ferramenta como um diferencial para apoiar a interação professor-aluno surdo em sala de aula. Destacamos a fala de Perseu na oficina 1, em que descreveu o Dicionário como uma oportunidade de se melhorar como professor, aprendendo a Libras:

\footnotetext{
Até uma observação que já aconteceu comigo, às vezes assim, eu cheguei um pouquinho antes para dar aula, e o aluno surdo chegou um pouquinho antes também e um outro aluno que não é surdo chegou um pouquinho antes também. Ele [o ouvinte] eu consigo estabelecer comunicação, ele consegue tirar alguma dúvida. Agora, até o momento que o intérprete chegava, tinha uma barreira mesmo, entre eu e ele. E eu ficava bem chateado e pensando "se ele tivesse alguma dúvida, ele não tava conseguindo tirar igual o outro estava tirando, pela barreira da comunicação”. Agora com este tipo de ferramenta, eu acho muito interessante que com um celular na mão você pelo menos já poder iniciar alguma conversa. (Perseu, oficina 1)
}

Atentando para a formação continuada, de acordo com Vasconcelos e Oliveira (2017) é de responsabilidade do profissional da educação entender os diversos contextos inerentes ao ensino para se atualizar, seja na forma de ensinar ou aprender. Assim, vivenciando a "Era da Informação", os autores afirmam que a compreensão das diversas linguagens pode ser aprimorada através do uso das tecnologias que circundam não somente o meio informal, mas também nos contextos de ensino. Nessa perspectiva, a aplicação das TICs através de ferramentas didáticas não servem somente à formação do aluno, mas também para a continuidade do aprimoramento profissional dos professores.

Perseu também refletiu durante a oficina sobre seu sentimento de frustração em relação à impossibilidade de comunicação direta com o aluno surdo. Silva et al. (2009) descrevem que a iniciativa de professores em estudar e aprender a Libras acarretaria em um aprendizado mais significativo do conteúdo pelo aluno Surdo. Consequentemente, a manifestação de interesse em usar o Dicionário para aprender a Libras pode auxiliar, assim como aponta Perseu, para iniciar uma conversa com seu aluno Surdo.

Ao levar em consideração as descrições, análises e discussões levantadas brevemente neste artigo percebemos que há ainda um longo caminho a ser percorrido de forma conjunta e colaborativa entre professores, intérpretes, comunidade Surda, técnicos e pesquisadores em busca da acessibilidade dos alunos Surdos matriculados em IES brasileiras. Apontamos também para a necessidade de busca constante e persistente a respeito do ensino e aprendizagem da Libras e de métodos de ensino, privilegiando o contexto educacional inclusivo.

\section{CONSIDERAÇÕES FINAIS}

Notamos grandes avanços a partir das conquistas legais almejadas pela comunidade Surda - como ilustram as leis previamente citadas: a Lei $n^{\circ}$ 10.436/2002 (BRASIL, 2002), o Decreto $n^{\circ}$ 5.626/2005 (BRASIL, 2005) e a Lei $n^{\circ}$ 13.409/2016 (BRASIL, 2016) - e entendemos que, a partir delas, ampliaram-se os estudos e debates no campo da LA, fortalecendo as discussões e embasando a realização de novas pesquisas.

As iniciativas que vêm sendo geradas abrem perspectivas de formação continuada e de desenvolvimento de conhecimentos científicos abrangendo a Libras. A continuidade de pesquisas e de divulgação científica contribuem para a troca de conhecimentos e para reflexão a partir de políticas linguísticas entre os usuários da língua, situados em diferentes instâncias de interação e de posicionamento social em relação a ela.

Nesse sentido, pesquisas como esta podem não somente elencar a opinião dos professores de alunos Surdos, mas também colaborar 
com o desenvolvimento das práticas formativas para os docentes de nível básico e superior, uma vez que, entendendo o contexto do aluno Surdo diretamente com os atores envolvidos, torna-se possível observar os desafios a serem enfrentados para uma possível inclusão. As especificidades linguísticas da Libras e o seu desconhecimento dos ouvintes elevam a dificuldade de difusão da cultura Surda e, consequentemente, da inserção dos alunos Surdos no ES.

Em relação à nossa pesquisa, identificamos que o trabalho proporcionou aos professores que colaboraram uma reflexão em relação ao uso do Dicionário Online Bilíngue Libras/Português em diferentes aspectos. Dentre eles, apontamos para a importância do reconhecimento da Libras como língua natural e regulamentada, para o entendimento dos professores no que se refere à complexidade da criação de sinais-termo, assim como a verificação da necessidade do ensino e aprendizagem da Libras como uma forma de diminuir a barreira linguística existente entre o Surdo e o professor ouvinte.

Foi possível verificar também que a implementação de uma formação continuada para os professores de alunos Surdos no ES seria eficaz para aprender mais sobre a Libras e ponderar a elaboração de metodologias e estratégias de ensino que permitam, ao menos alguns momentos, a interação direta em sala de aula entre professor e aluno. Salientamos aqui, ainda, o papel do profissional TILSP como um agente indispensável no processo de inclusão dos alunos Surdos no ES. A tríade professor-aluno-intérprete foram fundamentais para a mediação dos conhecimentos científicos advindos das áreas específicas estudadas por alunos Surdos e para a busca de sinais que conseguissem abranger o significado que os conceitos abarcam.

Uma das discussões protagonizadas durante a oficina demonstra, ainda, a emergência da catalogação, reconhecimento e padronização de sinais-termo. Nesse cenário, o Dicionário é compreendido com um suporte para o acolhimento e divulgação de sinais que vêm sendo encontrados. Para tal iniciativa - a catalogação de sinais e o estabelecimento de sinalário de áreas específicas , contribui com a criação de um histórico de sinais acadêmicos para a apropriação em outras disciplinas da mesma área ao longo dos cursos de graduação dos alunos Surdos atualmente matriculados na IES, assim como, facilita o processo de mediação linguística dos conhecimentos de alunos Surdos que venham a ingressar no ES. Esse processo está sendo realizado em colaboração com os próprios estudantes Surdos, professores e pesquisadores Surdos e ouvintes de diferentes instituições parceiras, assim como pela comunidade Surda local.

Ressaltamos que, após a realização das oficinas, os professores se tornaram mais conscientes dos fatores que circundam a cultura Surda e sua língua. Acreditamos, portanto, que este conhecimento irá repercutir nas ações desenvolvidas em sala de aula. Apesar da inicial falta de bagagem dos participantes sobre esses fatores, observamos a abertura para um processo reflexivo de apoiar a acessibilidade e permanência dos estudantes para a conclusão de seus cursos de graduação.

Concluímos que, para que haja um processo de ensino e aprendizagem adequado aos Surdos que estão matriculados no ES, é necessária a oferta de formação continuada aos docentes, com a promoção de atividades que demonstrem que a presença do aluno Surdo modifica o espaço da sala de aula com a presença do intérprete, e, principalmente, pelo fato de ser considerada a presença de um sujeito bilíngue e bicultural, que utiliza a Libras como principal meio de comunicação.

\section{REFERÊNCIAS}

ABREU, P. M. Recomendações para projetos de TICs para apoio a alfabetização com libras. 2010. Dissertação (Mestrado). Universidade Federal de Minas Gerais. 2010.

BARBOSA, L. R. S.; ELIAS, C. R. Tecnologias digitais nas comunidades surdas: modos de inclusão na sociedade. Revista Educação, Cultura e Sociedade, v. 1, n. 1, p. 126-142. 2011.

BRASIL. Lei no 4.024 Lei no 4.024, de 20 de dezembro de 1961. Fixa as Diretrizes e Bases da Educação Nacional. Recuperado: 1 maio 2016. Disponível: http://www.planalto.gov.br/CCIVIL 03/leis/L4024.htm. Acesso em: 31 ago. 2020. 
BRASIL. Lei n. ${ }^{9} 9.394$ Lei n. ${ }^{\circ}$ 9.394, de 20 de dezembro de 1996. Estabelece as diretrizes e bases da educação nacional. Brasília: Diário Oficial da União. Recuperado: 1 jan. 2016. Disponível: http://www.planalto.gov.br/ccivil 03/Leis/L9394.htm. Acesso em: 31 ago. 2020 .

BRASIL. Lei no 10.172 Lei no $^{\circ}$ 10.172, de 9 de janeiro de 2001. Plano Nacional de Educação. Recuperado: 1 junho de 2016. Disponível: http://www.planalto.gov.br/ccivil 03/leis/leis 2001/110172.htm. Acesso em: 31 ago. 2020.

BRASIL. Lei n ${ }^{\circ}$ 10.436, de 24 de abril de 2002. Dispõe sobre a Língua Brasileira de Sinais-Libras e de outras providências. Disponível em: http://www.planalto.gov.br/ccivil 03/leis/2002/L10436. Acesso em: 10 mai. 2020.

BRASIL. Decreto n ${ }^{\circ}$ 5.626, de 22 de dezembro de 2005. Regulamenta a Lei no 10.436, de 24 de abril de 2002, que dispõe sobre a Língua Brasileira de Sinais, e art. 3 do decreto lei $\mathrm{n}^{\circ} .5 .626$ de 22 de dez. 2005 . Disponível em: http://www.planalto.gov.br/ccivil 03/Ato2004/2005/D5626htm. Acesso em: 10 mai. 2020.

BRASIL. Lei n ${ }^{\circ}$ 13.005 Lei n 13.005, de 25 de junho de 2014. Aprova o Plano Nacional de Educação (PNE) e dá outras providências. Brasília. Recuperado: 10 jun. 2016. Disponível em : http://www.observatoriodopne.org.br/uploads/reference/file/439/documentoreferencia.pdf. Acesso em: 31 ago. 2020.

BRASIL. Lei $\mathrm{n}^{\circ}$ 13.409, de 28 de dezembro de 2016. Altera a Lei n 12.711 , de 29 de agosto de 2012, para dispor sobre a reserva de vagas para pessoas com deficiência nos cursos técnico de nível médio e superior das instituições federais de ensino. Disponível em: http://www.planalto.gov.br/ccivil_03/_ato2015-2018/2016/lei/L12409.htm. Acesso em: 10 mai. 2020.

BRITO, L. F. Por uma gramática de línguas de sinais. Rio de Janeiro: Tempo Brasileiro, 1995.

CASTANHO, D. M. FREITAS, S. N. Inclusão e prática docente no ensino superior. Revista Educação Especial, n. 27, p. 93-99, 2006.

CORRÊA, A. M. de S. et al. Jogos educativos digitais para o ensino de Libras disponíveis na Play Store. In: CONGRESSO INTERNACIONAL DE TECNOLOGIA NA EDUCAÇÃO - Tecedu, 16, 2018, Recife, PE. Anais... (on-line). Recife: Tecedu, 2018. Disponível: http://www.pe.senac.br/congresso/anais/2018/senac/index.html. Acesso: 11 abril. 2020.

DAROQUE, S. C. Alunos surdos no Ensino Superior: uma discussão necessária. 2011. Dissertação (Mestrado) - Programa de Pósgraduação em Educação, Universidade Metodista de Piracicaba, 2011.

DAVID, R. S. Formação de professores para o ensino superior: docência na contemporaneidade. Revista Periferia - Educação, cultura \& comunicação, v.9, n.2, p. 201-220, jul.-dez., 2017.

DICIONÁRIO DE LIBRAS. 2021 Disponível em: https://sistemas.cead.ufv.br/capes/dicionario/ Acesso em: 8 nov. 2021.

DUBOC, M. J. A formação do professor e a inclusão educativa: uma reflexão centrada no aluno surdo. Revista Educação Especial, n. 26, p. 1-5, 2005.

FAULSTICH, E. Base metodológica para pesquisa em socioterminologia: termo e variação. Brasília: Centro Lexterm, 1995.

FAULSTICH, E. Sinal-termo. Nota lexical: Centro Lexterm, 2014.

FERRE, N. P. de L. Identidade, diferença e diversidade: manter viva a pergunta. In: LARROSA, J; SKLIAR, C. (org.). Habitantes de Babel: políticas e poéticas da diferença. trad. Semíramis Gorini da Veiga. Belo Horizonte: Autêntica, 2001. p.195-214. 
FREIRE, M. M. LEFFA., V. J. A auto-heteroecoformação tecnológica. In: LOPES, L. P. da M. (org.). Linguística aplicada na modernidade recente: festschrift para Antonieta Celani. São Paulo: Parábola Editorial, 2013. P. 59-78.

GARRIDO, E.; CARVALHO, A. M. P. Reflexões sobre a prática e qualificação da formação inicial docente. Cadernos de Pesquisa, São Paulo, n. 107, p. 149-168, jul. 1999.

GEDIEL, A. L. B.; MOURÃO, V.L. A.; MIRANDA, I. M. A inclusão e suas práticas aspectos socioantropológicos da produção de materiais pedagógicos inclusivos para Surdos. Anuário Antropológico, v. 44, p. 135-158, 2019.

GESSER, A. Libras? que língua é essa?: crenças e preconceitos em torno da língua de sinais e da realidade surda. São Paulo. Parábola, 2009.

GESSER, A. O ouvinte e a surdez: sobre ensinar e aprender a Libras. 2. ed. São Paulo: Parábola Editorial, 2012.

LOPES, L. P. da. M. Da aplicação de linguística à linguística aplicada indisciplinar. In: PEREIRA, R. C.; ROCA, P. (org.). Linguística aplicada: um caminho com diferentes acessos. São Paulo: Contexto, 2011. p. 11-24.

MALACARNE, V.; OLIVEIRA, V. R. DE. A contribuição dos sinalários para a divulgação científica em Libras. Ensino Em Re-Vista, v. 25 , n. 2, p.289-305, 2018.

MENEZES, V.; SILVA, M. M.; GOMES, I. F. Sessenta anos de linguística aplicada: de onde viemos e para onde vamos. In: PEREIRA, R.C.; ROCA, P. Linguística aplicada: um caminho com diferentes acessos. São Paulo: Contexto, 2009. p. 25-50.

MINAYO, M. C. de S.; SANCHES, O. Quantitativo-qualitativo: oposição ou complementaridade?. Cadernos de Saúde Pública, v. 9 , n. 3, p. 237-248. 1993.

MIRANDA, I. M.; MOURÃO, V. L. A.; GEDIEL, A. L. B. As tecnologias da informação e comunicação (TICs) e os desafios da inclusão: a criação de aulas sinalizadas no contexto do ensino superior. Periferia, Duque de Caxias, v. 9, p. 223-242, 2017.

MORAN, J. M. Desafios que as tecnologias digitais nos trazem. In: MORAN, J. M. Novas tecnologias e mediação pedagógica. Campinas, São Paulo: Papirus, 2013. p. 30-35.

NÓVOA, A. Formação de professores e profissão docente. In: NÓVOA, A. (coord.). Os professores e sua formação. 3. ed. Lisboa: Dom Quixote, 1997.p. 93-114.

PIMENTA, M. R. G.; LIMA, L. I. G.; REIS, R. S. L. Análise dos processos mediacionais estabelecidos entre professor-intérprete de libras-estudante surdo em uma disciplina do curso de engenharia. Revista de Ciência Humanas, v. 18, n. 2, p. 1-17. 2018.

PONTE, J. P. da. Tecnologias de informação e comunicação na formação de professores: Que desafios? Revista Ibero-Americana de Educación, n. 24, p. 63-90, sep./dic. 2000.

QUADROS, R. M. de. Situando as diferenças implicadas na educação de surdos: inclusão/exclusão. Ponto de Vista: Revista de Educação e Processos Inclusivos, n. 5, p. 81-111, 2003.

QUADROS, R. M. de; KARNOPP, L. B. Língua de sinais brasileira: estudos linguísticos. São Paulo: Artmed, 2004. 
QUADROS, R. M. de; SCHMIEDT, M. L. P. Idéias para ensinar português para alunos Surdos. Brasília: MEC, SEESP, 2006.

SÁ-SILVA, J. R.; ALMEIDA. C. D.; GUINDANI. J. F. Pesquisa documental: pistas teóricas e metodológicas. Revista Brasileira de História \& Ciências Sociais, Rio Grande, v. I, p.1-14. 2009.

SILVA, R. de F. da. A ação do professor de ensino superior na educação física adaptada: construção mediada pelos aspectos dos contextos históricos, políticos e sociais. 2005. Dissertação (Mestrado) - Curso de Educação Física, Universidade Estadual de Campinas, Campinas, 2005.

SILVA, A. T. C. D., JUNIOR, M. M. R.; LIMA, F. J. D. O intérprete de Lingua Brasileira de Sinais no ensino fundamental e seu papel na escola comum. Recife: Universidade Federal de Pernambuco, [ca. 2009], 2008.

SILVA, S. C. da; CAMPOS, M. de F. H. A melhoria da qualidade da educação na escola pública: desafios ao uso das TIC. Estudos IAT, Salvador, v. 1, n. 3, p. 138-154, 2010.

SILVA, C. M. da; SILVA, D. N. H.; SILVA, R. C. da. Inclusão e processos de escolarização: narrativas de surdos sobre estratégias pedagógicas docentes. Maringá, Psicologia em Estudo, v. 19, n. 2, p. 261-271. 2014.

SKLIAR, C. Bilingüismo e biculturalismo: uma análise sobre as narrativas tradicionais na educação dos surdos. Revista Brasileira de Educação, n. 8, p.44-57, 1998.

SOUZA, I L.; BARCELOS, A. M. F. Onde está a LIBRAS? Uma reflexão sobre a língua brasileira de sinais no cenário da linguística aplicada brasileira. Domínios de Lingu@gem, Uberlândia, v. 10, n.3, p. 851-863, 2016.

SOUZA, A. L. S.; JÚNIOR, J. T. O uso de tecnologias (TIC) na produção de material didático bilíngue Libras/Português na Universidade Federal de Viçosa. Revista Forum, n. 33, p. 92-109, 2016.

STELLE, T. G.; STRIEICHEN, E. M. Os principais mitos sobre os surdos e a lingua de sinais. In: CONGRESSO NACIONAL DE EDUCAÇÃO - EDUCERE, 11., 2013, Curitiba. Anais eletrônicos... Curitiba: Educere, 2013. Disponível em: https://educere.bruc.com.br/CD2013/pdf/7380 4253.pdf. Acesso em: 8 nov. 2021.

TAVARES, K. C. do A.; OLIVEIRA, A. P. P. de. Libras no ensino de inglês mediado pelas novas tecnologias: desafios e possibilidades. Revista Brasileira de Linguística Aplicada, Belo Horizonte, v. 14, n. 4, p. 1045-1072, 2014.

VARGAS, J. S.; GOBARA, S. T. Sinais dos conceitos de massa, aceleração e força para Surdos na literatura nacional e internacional. Atas do IX Encontro Nacional de Pesquisa em Educação em Ciências (X ENPEC), Águas de Lindóia, SP, p. 1-8. 2013.

VASCONCELOS, C. A. de; OLIVEIRA, E. V. TIC no ensino e na formação de professores: reflexões a partir da prática docente. Revista Brasileira de Ensino Superior, v. 3, p. 112-132, 2017. 
XAVIER, A. N.; BARBOSA, P. A. Variação livre na libras: a realização com uma mão de sinais canonicamente feitos com duas. Revista (Con)Textos Linguísticos, Vitória, v. 8, n. 10.1, p. 6-24, 2014.

\section{() (1) $\odot \odot$}

Recebido em 01/06/20 Aceito em 04/09/2020. 